\title{
Impact of Serious Games on Health and Well-being of Elderly: A Systematic Review
}

\author{
Hai Nguyen ${ }^{\mathrm{a}}$, Diana Ishmatova ${ }^{\mathrm{b}}$, Tommi Tapanainen ${ }^{\mathrm{c}}$, Tapani N. Liukkonen ${ }^{\mathrm{d}}$, Niina Katajapuu ${ }^{\mathrm{e}}$, Tuomas Makila ${ }^{\mathrm{d}}$, \\ Mika Luimula ${ }^{\mathrm{e}}$ \\ Abo Akademi University ${ }^{\mathrm{a}}$, University of Johannesburg ${ }^{\mathrm{b}}$, University of Liege ${ }^{\mathrm{c}}$, University of Turku ${ }^{\mathrm{d}}$, Turku \\ University of Applied Science ${ }^{\mathrm{e}}$, \\ haintt@akane.waseda.jp ${ }^{\mathrm{a}},\left\{\text { ishmatova, tojuta@gmail.com }{ }^{\mathrm{b}, \mathrm{c}}\right\}_{2}$

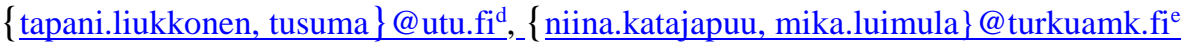

\begin{abstract}
Besides their entertainment value, serious games can have beneficial therapeutic effects for elderly people that improve their health and well-being. Games are likely to be accepted by elderly persons who have enjoyed games their lives, and because there are more and more of such elderly, it is important to investigate games as a therapeutic device. This research reviewed the literature focusing on the effects of games on elderly persons in three main types of effects: physical, cognitive, and social effects. The majority of reviewed papers focused on physical and cognitive effects, and were published in recent years, which emphasizes the relative novelty of this topic and suggests that future research will need to address social impact as well. In addition, while many papers claimed positive impacts as a result of using games, our review found that more attention should be given to research designs.
\end{abstract}

\section{Introduction}

The serious game industry has seen unprecedented development over the last decades with an enormous scope of applications beyond just entertainment. Some applications are currently used as new tools in education, rehabilitation, therapy, health promotion and monitoring, public policy and advertising. Video games that have other than entertainment-related purposes for a player are commonly referred as serious games [1]. Such purposes could be developing skills, conveying meaning, delivering a message, teaching a lesson, providing experience and emotions, or changing behavior and attitudes [2].

As with other technologies such as robotics or smart houses, there has been an increased interest in serious games for elderly people over the last few years. This can be largely attributed to the worldwide increase in aging population. According to [3], the proportion of the world's population aged 60 years or over reached $12 \%$ in 2013 and this proportion is growing. As a result, we will have more elderly people needing healthcare and support services than ever before.

Aging is typically associated with decline in cognition and perception, and an increase in physical impairments. Even if physical health and high cognitive functioning are important to successful ageing, they are not seen as only factors by the elderly people themselves. A number of studies reported that elderly people consider themselves aging successfully despite having physical illnesses and disabilities. [4], [5], [6], [7] found that the determinants of self-rated successful aging include optimism, resilience, cognitive ability, and physical and mental health-related quality of life.

Various cognitive and physical training programs have been developed to maintain and improve elderly persons' declining functions [8], [9], [10]. The potential of games as a tool for improving cognitive and physical health of older population has been gaining attention in the last years [11]. The engaging and entertaining features of serious games provide potential for its use as a tool for intergenerational interaction [21].

There is a lot of speculation in regards to the potential of the serious games to benefit the elderly people with fragmented evidence of their effectiveness. The aim of this paper is to conduct a systematic review on serious games for elderly people and their impacts with respect to health and well-being aspects of successful aging. Particularly, the review is expected to answer: What are the main impacts of the serious games for elderly people and how effective are they? and What are the research methods used in measuring the impacts?

The paper is organized as follows. Section 2, Section 3 and 4 focuses on research method, answering the research questions and analyzing the data. The impacts of serious games are discussed in Section 5. The final section outlines the implications and future research.

\section{Research Methodology}




\subsection{Data collection}

2.1.1. Keywords. As noted in the introduction, the present study aimed to analyze the literature and in the theme of "serious games for elderly people", to understand the impacts of serious games and research methods used. To serve these purposes, we employed keywords which relate to serious games and their effects to elderly players. We adopted keywords which were used by [12]. Two widely used terms, elderly and seniors, were used to identify research related to elderly people. The full set of keywords is given herein: ("computer games" OR "video games" OR "serious games" OR "simulation games" OR "game based learning" OR "online games") AND (elderly OR seniors) AND (evaluation OR impacts OR outcomes $O R$ effects OR learning OR education OR skills OR behavior OR attitudes OR engagement OR motivation OR affect).

2.1.2. Databases used and period searched. In this review, we used six databases, which have collected many publications in the field of health and social sciences, gerontology, and information communication technology as shown in Figure 1. We searched for the papers from year 2000 to present because based on our primarily search of previous studies, not many papers were found before year 2000 .

2.1.3. Reviewing process. This systematic literature review had four phases: planning, selection, extraction, and execution [13]. The planning phase consisted of designing the research strategy, defining clearly the purpose of the review, the key words and the databases as described above. The search was performed at the end of March 2015. The first and second author initially screened all titles and abstracts of references captured by the search strategy. The selection phase involved in eliminating those papers that clearly did not meet the requirements defined including the papers were not about elderly people, or they did not have empirical data or the age of participants were under 50. After full texts of the studies finally selected were downloaded, they were reviewed by four other independent researchers. Each reviewer was assigned to through the articles and decided whether each study did or did not meet the inclusion criteria. To be included in the review, papers had to (a) include empirical evidences relating to the outcomes of playing serious games for successful aging, (b) include an abstract, (c) research targets are elderly, who are over the age of 50 years (d) paper is written in English, and (e) articles are electronically retrievable as full texts or available locally.

The extraction phase examined the studies more closely to assess their quality. Data extraction was undertaken using Excel sheets to summarize the papers and classify the serious game impacts on the elderly. The principles and categories of [12] on serious games and [15] on games for elderly people were adopted as guidelines to extract information from previous studies.

After that, in the last phase, the reviews were checked by the second author, and if there were disagreements among researchers regarding the coding, the first author mediated the differences. This procedure serves two purposes. First, it maintains the explicitness and replicability of the study, permitting the reviewers to backtrack and re-evaluate their inclusion criteria and protocol at any point during the review. Second, it permits the reviewers to assess and establish inter-rater reliability [13].

\subsection{Data analysis}

2.2.1. Game technology categorization. The focus of the current study was on serious games for elderly people and they were categorized mainly based on the technical aspects and the desired impacts. The technical aspects of the games for elderly were identified based on the game delivery platform, which we also referred to the categorization of [12]. They were video console, $\mathrm{PC}$, online game, second life, mobile or alternate reality game (ARG) [12].

2.2.2. Game impact categorization. The categories which we used in reviewing and analyzing impacts of serious games were as follows:

Social, cognitive and physical impacts: In the field of computer games for the elderly, the motivations for elderly people to play games are categorized into four areas: entertainment, socializing with other people, mental exercise, and physical exercise [15], [16], [17]. [15] used these categories specifically from the perspective of game design for older adults, whereas [16] and [17] categorized the motivations and sources of enjoyment of the elderly gamers with compatible terms. For example, multiplayer games afford the possibility of social interactions while playing games, whereas puzzle and quiz - type games can be used for a purpose similar to crossword puzzles, that is to activate the mind. On the other hand, new user interfaces such as those that track the movements of the player are ideal for physical exercise. There are also serious games that are specifically intended to be used for learning a new skill or improving one's health [18].

Summarizing the above points, in this review, we categorize the effects of serious games to the elderly into social, cognitive, and physical effects. Social effects include effects that the game in question had in the 
entertainment and social interactions, but also include the potential effect on players' self-esteem. Cognitive effects are related on knowledge acquisition and effect on the progress of cognitive decline. Physical effects include variety of physical impacts, ranging from rehabilitation after injuries and impact on the amount of exercises done by the participants.

Positive, negative or no clear impacts: There is an ongoing debate about the impacts of serious games on the elderly players. Some researchers showed that playing a videogame was effective in improving cognitive and physical functions in the elderly. While some other studies have found no such evidence or even negative impact. Thus, in this review, we categorized the conclusion regarding the impacts into three groups: positive, negative and not clear. The paper was categorized in the positive impact group if after studying and conducting experiment, it concluded that playing serious games had significant impacts on the elderly. On the other hand, if the paper concluded that playing games negatively impacted on the elderly in the aspect which the paper tested, it was classified in the negative impact category. A paper was placed in the last group "no clear impact" if it found neither positive nor negative, or reported only certain impacts found or stated that further studies are required.

2.2.3. Research design and purposes. The papers were first categorized based on the country where they were conducted and the year when they were published. Then, they were coded according to the methodology (quantitative, qualitative, or both). Next, the research design of each paper was coded based on whether it used a randomized control trial (RCT), a quasi-experimental method, a survey, a qualitative method or mixed research design. In addition, the papers were checked regarding whether they used group comparisons (between groups or within the group) or not. If there were comparisons, the number of groups and the differences between groups were noted. Other information regarding the research methods, such as the sample, data collection and analysis, findings and conclusions were also noted.

In addition, papers were classified based on their primary research questions. We focused on papers which examined the potential impacts of playing games on the elderly game players. However, many studies had investigated games acceptance and game design. As the acceptance of games is considered as the basic positive outcomes of playing games, and game design is linked with acceptance, we also included papers that discussed the design and acceptance issues of games if the papers included empirical evidence concerning the social and health outcomes of games. Thus, we divided the research aims into two main groups: only evaluating the game impact and evaluating the game impact is one part of the study process which includes designing, developing, adopting the game and testing the impact.

\section{Results}

Total of 6592 papers were found and 24 papers were finally retained for the current review. The detail of selection process and information of reviewed papers are summarized in the Figure 1 and the appendix.

Initial search result

ACM: 30, BioMedCentral: 74, EBSCO: 3210, Emerald:

319, IEEE: 714, Science Direct: 2245. Total: 6592

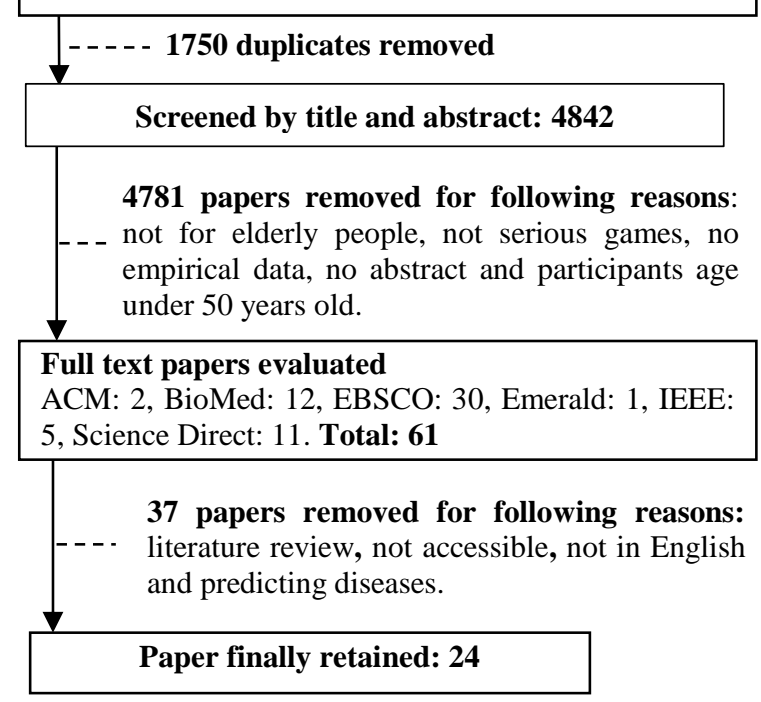

Figure 1. Selection Process

\subsection{Game technology categorization}

Technically the reviewed papers are in two main categories: console and personal computer (PC) based studies. From the 24 papers 13 were using commercially available consoles for their games. Out of these 13, 10 were using the Nintendo's Wii Fit which was launched and popular during the period represented by the papers. Microsoft's Xbox 360 with its motion sensing camera Kinect was used in two papers. Remaining two papers were using Nintendo's DS handheld console and a Xavix console.

Other half of the papers (10 papers) used PC as their main platform. Four of these were exergames, of which one was an existing open source game (StepMania) and three were custom games. Remaining six papers were targeting cognitive decline and disabilities, and out of these five had custom games, and one used an existing game (World of Warcraft). 
One paper did not study a particular game. The researchers conducted a survey and a follow-up interview to understand the perception and experiences of Chinese seniors regarding playing games in general.

\subsection{Research target, design and aims}

The target group in the majority of papers (17 out of 24 papers) was the group of healthy elderly people. The target group in seven other studies was the group of elderly people with disabilities caused by common old age diseases such as Alzheimer's disease, stroke, or a common accident such as a fall.

Regarding the primary research purposes of selected studies, more than $62.50 \%$ of studies aimed to investigate and evaluate the impacts of serious games on the elderly while in nine papers $(37.50 \%)$ evaluating the game effectiveness was just one task in proving the relevance of design frameworks/guidelines or in the technology acceptance process. For example, [19], [20]] described the whole process: the designimplementation-evaluation to suggest "design framework/guidelines" which was their final target. Most of the paper in this group (seven out of nine) used the qualitative, mixed-method or quasi-experimental design. Only two papers used the RCT research design while in the impact evaluation group, the main research method was RCT.

The majority of the included papers $(76.92 \%)$ reported quantitative data with only four (23.08\%) reporting qualitative data or mixed method which utilized interviews, observation with descriptive statistics, protocol analysis, and analysis of perspectives. Of the 20 studies which reported quantitative data, one utilized $(5.00 \%)$ survey design, five $(25.00 \%)$ utilized quasi-experimental designs, and $14(70.00 \%)$ used Randomized Control Trial (RCT) designs.

\subsection{Game impacts.}

$18(75.00 \%)$ out of 24 papers found the positive impacts of serious games on the elderly while six out of 24 papers, which are in the "no clear impact" group, stated that either further study was needed or the impact was not significantly proved. Regarding the impact categories, $15(62.50 \%)$ papers focused on the physical impact compared with six papers concentrated on the cognitive impact and only three papers considered the potential social impact of serious games on the elderly. While more than half of papers evaluating the health (i.e. cognitive and physical) impact of serious games on the elderly found positive results, only one out of three papers confirmed that serious games supported the elderly in socialization.

\section{Game impact analysis}

\subsection{Social impacts}

Only three papers in the current study were focused on social impacts. [20], [21] investigated the effects of video-game play on inter-generational interactions, without targeting people with any specific social or health conditions.

Though these two studies had similar goals, they were quite different in relation to the quality of provided evidence on game impacts. [21] measured the game effects through pre-test and post-test surveys and compared between two group of participants- those who played video games and those who were interacting freely with each other for the same amount of time. Noteworthy, in this study young people (with an average age of 17) and the elderly people were engaged in a game which was not specially designed as an intergenerational game. The study confirmed that playing video games had positive impact on intergroup anxiety, attitudes to other players, but these perceptions were mediated by the attraction towards a game partner. The study also confirmed the important role of game enjoyment for the older people in developing positive intergenerational perceptions. The latter was not found important for the younger players.

[20] reported on the design of digital tabletop game for promoting social interaction between children and older people. The study was based on the qualitative analysis of the game play experience. Observations allowed researchers to confirm that designed game stimulated social interaction both between the team members and their opponents during the game, while the interviews recorded the enjoyment of playing the game with each other.

Unlike the above studies, [19] reported on the study of a serious game specifically targeting Alzheimer and demented patients. The main aim of the game was to reduce the behavioral symptoms through "restoring selfesteem in patients who have gradually grown to consider themselves as a useless burden for their care givers" [19]. The actual impacts of the game were not reported in the paper as the tests were still in process at the moment of publication.

\subsection{Cognitive impacts}

Cognitive effects were the focus of six studies, investigating the improvements in visual attention, attentional control, visual, verbal and spacial working memory, speeded processing, spatial executive processing, verbal and non-verbal reasoning, problem 
solving as a result of video game interventions. The participants in five out of six studies were active seniors. Only one study targeted the elderly with the disabilities. Only two papers ([11], [22]) out of six papers used RCT to evaluate the cognitive impacts. The remaining four other papers used qualitative or mixed method and found positive results.

[11] investigated the effects of playing the Brain Age video game on global cognitive status, executive functions, attention, and processing speed of older people without any specific health conditions. The positive effects were confirmed only for executive functions and processing speed.

[22] tested the effectiveness of a number of online games for learning specifically developed for the older people. The cognitive effects of the games were tested on community-dwelling seniors volunteered for the study and included psychomotor speed, attention, decision-making, working memory and new learning. However, the games were not found to have a positive impact on any of the assessed cognitive functions.

In their study, [23] confirmed the effectiveness of playing World of Warcraft on older peoples' cognitive abilities confirming the improvement of spatial orientation ability and attentional control. [24] investigated the impacts of intervention using Xbox-360 equipped Kinect sensor with different durations on selective attentions of older people with disabilities. Their study confirmed that playing video games for longer durations (8-week intervention) have immediate, carry-forward and overall effects on elderly people, while shorter interventions have limited effects, improving only some aspects of selective attention and having limited carry-forward and overall effects [24].

The primary purposes of the remaining two papers were mainly to report game design and acceptance in relation to the cognition. [25] informed a cognitive wellness system named Abueparty which contains game like everyday entertainment activities for the cognitive stimulation of worried-well elders. [26] on the other hand, investigated perceived impacts of playing computer game on learning of computer skills and life satisfaction of older people. While the focus was slightly different, both studies relied on a similar methodology deploying questionnaires based on Davis' Technology Acceptance Model (TAM), evaluating participants experience with playing games. However, while [25] assessed the experience of users with their developed games, [26] did not focus on a specific game and aimed to reveal how playing computer games generally affects perceived learning of computer skills and life satisfaction. In any of these cases, therapeutic impacts of the developed frameworks or games were not tested.

\subsection{Physical impacts}

Among 15 papers assessing impacts of video games on physical conditions, two papers examined different physical impacts on stroke patients, one- on mild stage Alzheimer patients, one -on long term patients, one - on elderly recent fallers, and 10 papers investigated different physical impacts on either home or community dwelling healthy elderly people.

Most of the ten papers, which the participants were healthy elderly people ([27], [28], [29], [30], [31], [32], [33], [34], [35], [36]), focused on balance and postural control. Eight of them showed improvement in balance after exergame program. Only study of [27] did not show any positive impact after Nintendo Wii exercise, while the study of [32] suggested the further investigation. Four studies had the comparison group without having any exercise. Three other studies described the exercise program conducting in the comparison group. For example, [32] examined the foot placement accuracy with two different exercise methods. They found the balance and strength training program with exergaming part (dance video game) to improve the gait velocity and single support part in walking cycle significantly better than the balance and strength training program alone,

The diagnosed based analysis included three diagnose groups (stroke, Parkinson, and Alzheimer) of the persons whose cognitive status may be altered and this may have the impacts on their physical functioning. Both studies with the stroke patients ([37], [38]) examined the exergaming impacts on upper arm motor recovery but used different setting and measures such as Fugl-Meyer test (FMA), modified Barthel index (MBI) and virtual environment and haptic device as exercising and measurement tool. Despite of that, both studies showed some improvements in upper extremity function after exercise programs for stroke patients. Motor recovery after stroke is based both on cognitive and physiological factors.

The study of [39] examined the walking abilities and balance of mild stage Alzheimer patients after exergame program. Walking and balance are both very complex motor, sensor and cognitive phenomenas and are affected in dementia as it progresses. Study showed some improvements in balance after exergame program but it was not superior compared to walking exercise program. [40] also examined the impacts on upper extremity range of motion and functioning but for longterm patients. Pendulum-style movement exercises are used in shoulder rehabilitation when the joint is stiff and range of motion decreased. The study showed significant improvement after exergaming with Wii Fit Bowling for a period four weeks.

[41] examined benefits of exergame program (Wii Fit) in balance and fear of falls in recent fallers 
population. The only statistically significant difference they found in pre-post setting was in Falls efficacy scale (FES-I) in standard care group, not in exergame group.

\section{Discussion}

First, even though we found only 24 papers evaluating the impact of games on the well-being of the elderly, the research topic is clearly of global interest as the studies have been conducted in various different countries such as in Australia (2 papers) and New Zealand, in America (U.S with 6 papers, Canada and Mexico), in Europe (e.g. France with 2 papers, Sweden and Denmark), and in Asia (e.g. Japan, Korea, Singapore and Taiwan). This research topic is relatively new and emerging since the first paper with empirical data in our review was found published in the year 2009. Most of the papers were published in 2012 (12 papers) and were followed by six papers in 2013 (Figure 1).

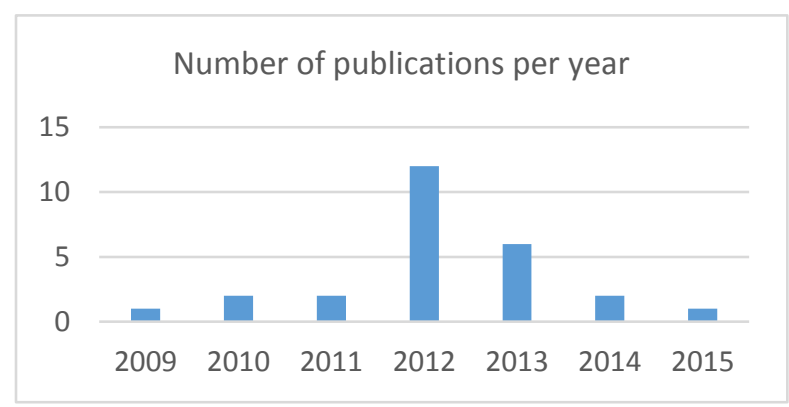

Figure 2. Number of publication per year

Regarding the game impact, physical impacts were discussed most often, followed by cognitive impacts and social impacts. This might not be surprising as old age is associated with deterioration in physical and mental faculties. However, social engagement has found to be an important factor influencing not only subjective emotional well-being but also brain development and functionality [42]. Two most important self-reported elements of successful aging are self-acceptance and active engagement, which among others means maintaining social relationships with friends, family and young people [43]. Epidemiological studies have also found social relationships to be important in maintaining cognitive health and reducing mortality in old age [44]. The lack of social relationships on the other hand, contributes to pre-symptomatic dementia [45].

The existing video gaming literature suggests that on one hand, the desire to socialize with other players is an important motivator for playing video games. On the other hand, there is an empirical evidence showing that playing video games can facilitate social interaction between players ([46], [47]), and that such in-game interactions and friendships are often transformed into real life friendships [48]. In addition, co-playing can in some cases increase the enjoyment derived from playing video games [48], creating a virtuous cycle. Whether these findings are true for older population is still to be seen, but they do suggest there is a potential that video games can improve social engagement, including intergenerational engagement of older adults [21].

For the impact results, $75 \%$ of papers found the positive impacts of serious games on the well-being of the elderly. However, it is important to point out the following reservations in interpreting these results. The size of study population was wide ranging from 16-116. Population background was heterogeneous in age and health status varying from 50 year to over 80 year old people, from healthy people to those who had multiple diseases, chronic disease or other comorbidities. Study settings varied from qualitative studies to double blinded three arm randomized controlled studies. In other words, these studies differed in their measures, which makes them difficult to compare.

For example, in evaluating the physical impacts, one of the main focuses was on balance and postural control. Balance is an interaction of muscle strength, joint range of motion, reaction time, visual, sensory and proprioception inputs from peripheral receptors to central nervous system and its right timed reactions in musculoskeletal system. It is challenging to make a proper research setting to achieve valid and reliable conclusions of certain intervention impacts on balance. The well-known measurements used in the reviewed papers to measure the balance were Berg balance scale, Timed up and go test, 8 foot timed up and go test (part of Fullertons test), Tinetti test and Good Balance force platform apparatus. Depending on the setting, some studies used the same measures to assess the mobility or walking ability or over all physical functioning. However, all the measures mentioned above do not offer equivalent units for the comparison among the studies.

It is also interesting to note that most of the papers that confirmed the positive results used RCT method. The majority of studies that used RCT were studies evaluating the physical impacts.

Table 1. Study design and impact results

\begin{tabular}{|l|c|c|c|}
\hline \multicolumn{1}{|c|}{ Study design } & \multicolumn{2}{|c|}{ Impact Results } & Total \\
\hline & Positive & $\begin{array}{c}\text { Not } \\
\text { clear }\end{array}$ & \\
\hline Survey & 1 & & 1 \\
\hline Quasi-experimental & 3 & & 3 \\
\hline RCT mixed & 12 & 4 & 16 \\
\hline $\begin{array}{l}\text { Qual. or } \\
\text { method }\end{array}$ & 2 & 4 \\
\hline Total & 18 & 6 & 24 \\
\hline
\end{tabular}

Furthermore, whereas 14 (93.33\%) papers out of 15 papers in the physical impacts used RCT design, only one study ([21]) in the social impacts used a control group and reported conditional positive effects of 
playing video games on attitudes and anxiety towards the other age group. Two other studies ([19], [20]) in this group represent small scale case-studies reporting a design of new games to improve social skills and experiences, and primarily focusing on design implications. They did not use any between group comparisons to validate the results and not provide a strong evidence of the game impacts.

However, the way RCT was used in some cases is problematic. For example, in four studies the comparison group did not have any exercise. Thus, it is obvious that the exergame group had better results in between-group comparisons in those studies. In addition, it was not clear whether the duration and frequency of interventions were sufficient. In their study [28] examined lower extremity muscle strength. Intervention lasted only 10 weeks with two exercise periods with Wii Fit/week. While to have the anabolic changes in muscle cells, the exercise should be progressive by increasing the resistance or repetitions, there should be at least three exercises per week and intervention should last 12 weeks. Therefore, the changes, which they found in static muscle contraction, might be due the increase in neural activity [49]. Then it is obvious they found the positive changes in static muscle contraction (force development) and Timed Up and Go test, which demands fast reaction with own body weight. Notable is that comparison group did not have any resistance or other physical exercise.

On the other hand, study of [27] did not show any improvement in balance after Nintendo Wii exercise, but the intervention lasted only three weeks with two times/week. To improve all the factors affecting on balance, three weeks might be too short period to have improvements. In spite of short experiment period, the setting of [27] was one of the most complete.

\section{Conclusions and future directions}

In this review, we found that health issues (including physical and mental problems) were the main focus of game studies for elderly while there were only three papers focusing on social impacts of video games and two of them primarily focusing on game design implications. This was surprising when considering the dominating research target group was active seniors (as the participants in 17 papers were healthy elderly while seven papers were patients) and the importance of social engagement on subjective well-being and healthier brain aging as discussed in section 5 .

This could be due to methodological challenges as there is no standardized definition of social engagement. [45] stated that the definition of social engagement is close to the definition of social networks defined by [50] as "the set of people with whom an individual is directly involved". They suggest there are four major aspects of social networks particularly relevant for the older population: network structure and interaction, social exchange, social engagement, and subjective network perceptions. The existing gaming literature investigates social engagement through social interactions of players including the number and quality of friends, inclusion of friends and family within the game, the impact of gaming on real life friendship, anxiety, attitudes to other players, attraction towards co-players, perceived loneliness and belonging, self-esteem, affection, and game play enjoyment etc. which in turn are measured with a variety of scales ([21], [52], [53]). While perceptions constructs (affection, anxiety etc.) have established psychometric scales, measuring game impacts on structural and functional components of social networks is more methodologically and resource demanding and, which, perhaps, may partially explain the lack of studies focused on social impacts of video games.

There was a large variation of outcomes and measures to show the impacts of gaming on physical and cognitive conditions. The research design used in the papers also calls for more accuracy in the use of control groups, choice of treatment for control and experimental groups, duration of interventions, use of randomization. Therefore, to facilitate the game impact evaluation and reliability of its results, there is a need for methodological guidelines and standardized scales for measuring impacts

Despite these challenges, it is worth saying that there were many positive impacts found in most of these reviewed studies. However, more detailed studies with larger study population is still needed before recommending the health policy makers to adopt this novel, future using games in improving the health and well-being of elderly. It would also be interesting to have economic analysis of these new methods to see if they are cost-effective enough compared to the traditional ones. Besides capturing game impacts as such, it would be interesting to investigate possible connection between a game type and impact it provides.

The current review revealed an obvious prevalence of Wii Fit and Kinect-based exergames in rehabilitation. However, it would be interesting to look beyond the platforms and investigate what aspects of video games provide the impacts. For instance, [20] argue that it was the use of tangible play in combination with a guessing element is what facilitated social interaction. Different game aspects may have different impacts on physical, cognitive and social conditions. One of the challenges of testing that proposition is finding proper classification for the games and/or their components. Existing classifications of game genres were developed for entertainment games and their relevancy for serious 
games is questionable. Moreover, games genres don't necessary reflect cognitive, motoric and social demands and skills a game requires. Thus, there a need for a new categorization of video games that would allow to trace the impacts of various aspects of video games.

\section{References}

[1] de Morais, Wagner Ourique and Wickström, Nicholas (2011), "A Serious Computer Game to Assist Tai Chi Training for the Elderly", IEEE 1st International Conference on Serious Games and Applications for Health (SeGAH 2011), Braga, Portugal, 16-18 November 2011.

[2] Marsh, T., "Serious games continuum: Between games for purpose and experiential environments for purpose", Entertainment Computing, 2011, 2, pp. 61-68.

[3] U.N (United Nations), Department of Economic and Social Affairs, Population Division (2013). World Population Ageing 2013. ST/ESA/SER.A/348.

[4] von Faber M, Bootsma-van der Wiel A, van Exel E et al., "Successful aging in the oldest old: who can be characterized as successfully aged?", Arch Intern Med, 2001, 161:2, pp-694700.

[5] Montross LP, Depp C, Daly J et al., "Correlates of selfrated successful aging among community-dwelling older adults", Am J Geriatr Psychiatry, 2006; 14, pp. 43-51.

[6] Strawbridge WJ, Wallhagen MI, Cohen RD., "Successful aging and well-being: self-rated compared with Rowe and Kahn", Gerontologist, 2002, 42, pp. 727-33.

[7] Vahia IV, Meeks TW, Thompson WK et al., "Subsyndromal depression and successful aging in older women”, Am J Geriatr Psychiatry, 2010, 18, pp. 212-20.

[8] Gardner M. M., Robertson M. C., Campbell A. J., "Exercise in preventing falls and fall related injuries in older people: a review of randomized controlled trials", Br J Sports Med, 2000, 34, pp. 7-17.

[9] Erickson KI, Prakash RS, Voss MW, Chaddock L, Hu L, Morris KS, White SM, Wójcicki TR, McAuley E, Kramer AF., "Aerobic fitness is associated withhippocampal volume in elderly humans", Hippocampus, 2009, 19(10), pp. 1030 1039.

[10] Smith, G. E., Housen, P., Yaffe, K., Ruff, R., Kennison, R. F., Mahncke, H. W., et al., "A cognitive training program based on principles of brain plasticity: results from the Improvement in Memory with Plasticity-based Adaptive Cognitive Training (IMPACT) study", Journal of the American Geriatrics Society, 2009, 57 (4), pp. 594-603.

[11] Nouchi R, Taki Y, Takeuchi H, Hashizume H, Akitsuki $\mathrm{Y}$, et al. "Brain Training Game Improves Executive Functions and Processing Speed in the Elderly: A Randomized Controlled Trial", PLoS ONE, 2012, 7(1).

[12] Connolly, Thomas M., Boyle, Elizabeth A., MacArthur, Ewan, Hainey, Thomas, Boyle, James M., "A systematic literature review of empirical evidence on computer games and serious games", Computers \& Education, 2012, 59, pp. 661-686.

[13] Okoli, C., Schabram, K., "A Guide to Conducting a Systematic Literature Review of Information Systems Research", Sprouts: Working Papers on Information Systems, 2010, 10 (26).

[15] IJsselsteijn, W., Nap, H. H., de Kort, Y., Poels, K.,
"Digital Game Design for Elderly Users", in the proceeding of Future Play Toronto, Canada, 2007, November 15-17.

[16] Cota, T. T., \& Ishitani, L. "Motivation and benefits of digital games for the elderly: a systematic literature review", Revista Brasileira de Computação Aplicada, 2014, 7(1), pp. 216.

[17] De Schutter, B., \& Brown, J. A. "Digital Games as a Source of Enjoyment in Later Life", Games and Culture, 2016, 11(1-2), pp. 28-52.

[18] Lebram M., Backlund P., Engström H., and Johannesson M., "Design and Architecture of Sidh-a Cave Based Firefighter Training Game", in Design and Use of Serious Games, Kankaanranta, M. and Neittaanmäki, P. Eds. Springer, 2009, pp. 19-31.

[19] Benveniste S., Jouvelot, P., Pin, B., Pequignot, R., “The MINWii project: Renarcissization of patients suffering from Alzheimer's disease through video game-based music therapy", Entertainment Computing, 2012, 3, pp.111-120 [18] [20] Mahmud, Abdullah Al, Mubin, Omar, Shahid, Suleman, Martens, Jean-Bernard, "Designing social games for children and older adults: Two related case studies", Entertainment Computing, 2010, 1, pp.147-156

[21] Chua, Puay-Hoe, Jung, Younbo, O. Lwin, May, Theng, Yin-Leng, "Let's play together: Effects of video-game play on intergenerational perceptions among youth and elderly participants", Computers in Human Behavior, 2013, 29, pp. 2303-2311

[22] Bozoki, Andrea, Radovanovic, Mirjana, Winn, Brian, Heeter, Carrie, Anthony, and James C. Effects of a computerbased cognitive exercise program on age-related cognitive decline. Archives of Gerontology and Geriatrics, 2013, 57, pp. $1-7$

[23] Whitlock, Laura A., Collins McLaughlin, Anne, Allaire, Jason C., "Individual differences in response to cognitive training: Using a multi-modal, attentionally demanding gamebased intervention for older adults", Computers in Human Behavior, 2012, 28, pp. 1091-1096.

[24] Chen, Shang-Ti, Chiang, I-Tsun, Liu, Eric Zhi-Feng, Chang, Maiga. "Effects of improvement on selective attention: developing appropriate somatosensory video game interventions for institutional-dwelling elderly with disabilities", The Turkish Online Journal of Educational Technology, 2012, Vol. 11 (4).

[25] Meza-Kubo, Victoria and Moran, Alberto L., "UCSA: a design framework for usable cognitive systems for the worried-well", Pers Ubiquit Comput., 2013, 17, pp. 1135-45. [26] Wang, Feihong, Lockee, Barbara B., Burton, John K., "Computer game-based learning: perceptions and experiences of senior Chinese adults", Journal of educational technology systems, 2011-2012, Vol. 40(1), pp. 45-58

[27] Franco, J. R., Jacobsb, K., Inzerilloc, C. \& Kluzik, J., "The effect of the Nintendo Wii Fit and exercise in improving balance and quality of life in community dwelling elders", Technology and Health Care, 2012, 20, pp. 95-115

[28] Jorgensen, M. G., Laessoe, U., Hendriksen, C., Nielsen, O., Bruno F. \& Aagaard, P., "Efficacy of Nintendo Wii Training on Mechanical Leg Muscle Function and Postural Balance in Community-Dwelling Older Adults: A Randomized Controlled Trial", J Gerontol A Biol Sci Med Sci., 2013 July; 68(7):845-852.

[29] Konstantinidis, E. I., Billis, A. S., Mouzakidis, C. A., 
Zilidou, V. I., Antoniou, P. E. and Bamidis, P. D., "Design, implementation and wide pilot deployment of FitForAll: an easy to use exergaming platform improving physical fitness and life quality of senior citizens", Journal of Biomedical and Health Informatics, 2014.

[30] Lai, Chien-Hung, Peng, Chih-Wei, Chen, Yu-Luen, Huang, Ching-Ping, Hsiao, Yu-Ling, Chen, Shih-Ching, "Effects of interactive video-game based system exercise on the balance of the elderly", Gait \& Posture, 2013, 37, pp. 511515.

[31] Laver, Kate, George, Stacey, Ratcliffe, Julie, Quinn, Steve, Whitehead, Craig, Davies, Owen Crotty, Maria. Use of an interactive video gaming program compared with conventional physiotherapy for hospitalised older adults: a feasibility trial. Disability \& Rehabilitation, 2012; 34(21): 1802-1808.

[32] Pichierri, Giuseppe, Murer, Kurt and de Bruin, Eling D. A cognitive-motor intervention using a dance video game to enhance foot placement accuracy and gait under dual task conditions in older adults: a randomized controlled trial. BMC Geriatrics 2012, 12:74

[33] Rendon, A. A., Lohman, E. B., Thorpe, D., Johnson, E. G., Medina, E., Bradley, B. The effect of virtual reality gaming on dynamic balance in older adults. Age and Ageing 2012; 41: 549-552

[34] Schoene, Daniel, Lord, Stephen R., Delbaere, Kim, Severino, Connie, Davies, Thomas A., Smith, Stuart T. A Randomized Controlled Pilot Study of Home-Based Step Training in Older People Using Videogame Technology. PLoS ONE. 2013, 8(3).

[35] Taylor, Lynne M., Maddison, Ralph, Pfaeffli, Leila A., Rawstorn, Jonathan C., Gant, Nicholas, Kerse, Ngaire M. Activity and Energy Expenditure in Older People Playing Active Video Games. Archives Physical Medicine Rehabilitation. 2012, Vol. 93

[36] Toulotte, Claire, Toursel, Cindy and Olivier, Nicolas. Wii Fit $\circledast$ training vs. Adapted Physical Activities: which one is the most appropriate to improve the balance of independent senior subjects? A randomized controlled study. Clinical Rehabilitation. 2012, 26(9), pp.827-835.

[37] Broeren, Jurgen, Sunnerhagen, Katharina S. and Rydmark, Martin. Haptic virtual rehabilitation in stroke: transferring research into clinical practice. Physical Therapy Reviews. 2009 Vol.14, N. 5.

[38] Shin, Joon-Ho, Ryu, Hokyoung and Jang, Seong Ho. A task-specific interactive game-based virtual reality rehabilitation system for patients with stroke: a usability test and two clinical experiments. Journal of NeuroEngineering and Rehabilitation. 2014, 11:32

[39] Padala, Kalpana P., Padala, Prasad R., Malloy, Timothy R., Geske, Jenenne A., Dubbert, Patricia M., Dennis, Richard A., Garner, Kimberly K., Bopp, MelindaM., Burke, William J. and Sullivan, Dennis H. Wii-Fit for Improving Gait and Balance in an Assisted Living Facility: A Pilot Study. Journal of Aging Research. 2012, 6 pages

[40] Hsu, Jason K., Thibodeau, Richard, Wong, Stephanie J., Zukiwsky, Daniel, Cecile, Sara and Walton, David M. A "Wii" bit of fun: The effects of adding Nintendo Wiis Bowling to a standard exercise regimen for residents of longterm care with upper extremity dysfunction. Physiotherapy Theory and Practice. 2011, 27(3):185-193.
[41] Williams, Marie A., Soiza, Roy L., Jenkinson, Alison McE., Stewart, Alison. Exercising with Computers in Later Life (EXCELL) - pilot and feasibility study of the acceptability of the Nintendo ${ }^{\circledR}$ WiiFit in community-dwelling fallers. BMC Research Notes. 2010, 3:238.

[42] Cole, S.W., 2014. Human social genomics. PLOS Genet. 10, e1004601.

[43] Reichstadt, J. Sengupta, G., Depp, C. A., Palinkas, L. A., Jeste, Dilip V., "Older Adults' Perspectives on Successful Aging: Qualitative Interviews", American Journal of Geriatric Psychiatry, 2010, 18 (7), pp. 567-75.

[44] Zunzunegui, M.V., Alvarado, B.E., Del Ser, T., Otero, A., "Social networks, social integration, and social engagement determine cognitive decline in community-dwelling Spanish older adults", J. Gerontol. B Psychol. Sci. Soc. Sci., 2003, 58, S93-S100.

[45] Ballesteros S., Kraft E., Santana, S., Tziraki C., "Maintaining older brain functionality: A targeted review" Neuroscience and Biobehavioral Reviews, 2015, 55, pp. 453477.

[46] Steinkuehler, C., \& Williams, D., "Where everybody knows your (screen) name: Online games as "third places", Journal of Computer-Mediated Communication, 2006, 11 (4), 885-909.

[47] Yee, N., "The demographics, motivations, and derived experiences of users of massively-multi-user online graphical environments", Teleoperators and Virtual Environments, 2006, 15(3), pp. 309-329.

[48] Bowman N. D., Kowert, R., Cohen, E., "When the ball stops, the fun stops too: The impact of social inclusion on video game enjoyment", Computers in Human Behavior, 2015, 53, pp. 131-139.

[49] Häkkinen K, Newton U, Gordon S, McCormick M,Volek J,Nindl B, Gotshalk L,Campbell W, Evans W, Häkkinen A, Humphries B and Kraemer W. Changes in muscle morphology, electromyographic activity and force production charasteristics during progressive strength training in young and older men. Journal of gerontology: Biological sciences 1998. Vol 53A, No 6, B415-B423.

[50] Wrzus, C., Hanel, M., Wagner, J., Neyer, F.J., 2013. Social network changes and life events across the life span: a meta-analysis. Psychol. Bull. 139, 53-80.

[52] Jung, Y., Koay, J. L., Ng, J. S., Wong, G. L. C., \& Lee, K. M., "Games for a better life: Effects of playing Wii games on the well-being of seniors in a long-term care facility", the Sixth Australasian Conference on Interactive Entertainment, Sydney, Australia, 2009.

[53] Ghuman, D., Griffiths, Mark D., “A Cross-Genre Study of Online Gaming: Player Demographics, Motivation for Play, and Social Interactions Among Players", International Journal of Cyber Behavior, Psychology and Learning, January-March 2012, 2(1), pp. 13-29.

Acknowledgement: We would like to acknowledge the valuable contributions of the Japan Foundation and the European Union for making this research possible. 
Appendix: Study design and Impact analysis of reviewed papers

\begin{tabular}{|c|c|c|c|c|c|c|c|}
\hline \multirow[t]{2}{*}{ Articles } & \multicolumn{5}{|c|}{ Study design } & \multicolumn{2}{|l|}{ Impact analysis } \\
\hline & Target & Purposes & Method & Sample & Measurement & Investigation & Result \\
\hline \multicolumn{8}{|l|}{ Social impacts } \\
\hline Benveniste et al. 2012 [17] & $\begin{array}{l}\text { Dementia \& } \\
\text { Alzheimer }\end{array}$ & Partly & Qual. & 16 & & Behavioral issues \& Game design & Not yet \\
\hline Chua et al. 2013 [20] & Active & Fully & RCT & 74 & IAn, GA, IAt \& GE & Inter-generational interactions & Positive \\
\hline Mahmud et al. $2010[18]$ & Active & Partly & Mixed & 16 & & $\begin{array}{l}\text { Inter-generational interactions \& } \\
\text { Game design }\end{array}$ & Not yet \\
\hline \multicolumn{8}{|l|}{ Cognitive impacts } \\
\hline Bozoki et al. 2013 [21] & Active & Fully & RCT & $\begin{array}{l}66(60-80 \\
\text { yrs) }\end{array}$ & CogState & Cognitive changes for learning & $\begin{array}{l}\text { Relatively } \\
\text { small }\end{array}$ \\
\hline Chen et al. 2012 [23] & Disabilities & Partly & Mixed & $\begin{array}{l}58(65-92 \\
\text { yrs })\end{array}$ & $\begin{array}{l}\text { Vienna Test, } \\
\text { MMSE }\end{array}$ & Selective attention \& Game design & Positive \\
\hline $\begin{array}{l}\text { Meza-Kubo \& Moran } \\
(2013) \text { [24] }\end{array}$ & Active & Partly & Survey & $\begin{array}{l}29(58-83 \\
\mathrm{yrs})\end{array}$ & PU, PEOU \& PUE & Cognitive wellness \& Acceptance & Positive \\
\hline Nouchi et al. 2012 [6] & Active & Fully & RCT & 32 & $\begin{array}{l}\text { MMSE, FAB, D-CAT, DS-F \& DS-B, Cd } \\
\& \text { SS) }\end{array}$ & 4 cognitive functions & Limited \\
\hline Whitlock. 2012 [22] & Active & Fully & $\begin{array}{l}\text { Quasi- } \\
\text { experimental }\end{array}$ & $\begin{array}{l}39(60-77 \\
\text { yrs })\end{array}$ & $\begin{array}{l}\text { MRT, OPT, PFT, DSST, ST, PM, ECB } \\
\text { Memory, SVT }\end{array}$ & Cognitive abilities & Positive \\
\hline Wang et al (2011) [25] & Active & Partly & Mixed & 60 & Playing computer game & $\begin{array}{l}\text { Computer skills, life satisfaction \& } \\
\text { Acceptance }\end{array}$ & Positive \\
\hline \multicolumn{8}{|l|}{ Physical impacts } \\
\hline Broeren et al. 2008 [37] & Stroke & Fully & $\begin{array}{l}\text { Quasi- } \\
\text { experimental }\end{array}$ & 48 & BBT, AMPS, ABILHAND & Upper arm motor recovery & Positive \\
\hline Franco et al. 2012 [26] & Active & Fully & RCT & $\begin{array}{l}32(63-90 \\
\mathrm{yrs})\end{array}$ & BBS, TG \& BA, \& SF-36 & Balance \& risk of falls & No \\
\hline Hsu et al. $2011[40]$ & Long-term patients & Fully & RCT & 34 & NHPPT, modified PACES, NRS \& AROM & Upper extremity functions & Positive \\
\hline Jorgensen et al. 2013 [27] & Active & Fully & RCT & (over $65 \mathrm{yrs})$ & MVC, RFD, CoP-VM, TUG, FES-I & Balance & Positive \\
\hline $\begin{array}{l}\text { Konstantinidis et al. } 2014 \\
\text { [28] }\end{array}$ & Active & Partly & RCT & 116 & SUS, SUMI, Fullerton \& WHOQoL & $\begin{array}{l}\text { Physical fitness, quality of life \& } \\
\text { Game development }\end{array}$ & Positive \\
\hline Lai et al. 2013 [29] & Active & Fully & RCT & $\begin{array}{l}20(68-77 \\
\mathrm{yrs})\end{array}$ & $\begin{array}{l}\text { XMSS, BBS, TUG, MFES, UST \& Catsys } \\
2000\end{array}$ & Balance & Positive \\
\hline Laver et al. 2012 [30] & Active & Fully & RCT & $\begin{array}{l}44(80-90 \\
\text { yrs) }\end{array}$ & $\begin{array}{l}\text { TUG, SPPB, Modified MBBS, TIADL, } \\
\text { FIM, ABC \& EQ5D }\end{array}$ & Balance & Positive \\
\hline Padala et al. 2012 [39] & Alzheimer & Fully & RCT & 22 & BBS, TT, TUG & Walking abilities \& balance & Positive \\
\hline Pichierri et al. 2012 [31] & Active & Fully & RCT & $\begin{array}{l}31(81-90 \\
\text { yrs) }\end{array}$ & FP, GP \& FE & Balance & Not yet \\
\hline Rendon et al. 2012 [32] & Active & Fully & RCT & $\begin{array}{l}34(77-89 \\
\text { yrs) }\end{array}$ & $8 \mathrm{ft} \mathrm{UG}, \mathrm{ABC} \&$ GDS & Balance & Positive \\
\hline Schoene et al. 2013 [33] & Active & Fully & RCT & $\begin{array}{l}32(73-82 \\
\text { yrs) }\end{array}$ & CSRT, PPT, TUG, AST \& TMT & Balance & Positive \\
\hline Shin et al. 2014 [38] & Stroke & Partly & RCT & 23 & FMA, MBI \& adverse effects & $\begin{array}{l}\text { Upper extremity functions \& Game } \\
\text { design }\end{array}$ & Positive \\
\hline Taylor et al. 2012 [34] & Active & Fully & $\begin{array}{l}\text { Quasi- } \\
\text { experimental }\end{array}$ & $\begin{array}{l}19(65-87 \\
\mathrm{yrs})\end{array}$ & METs, mini-BESTest, BCS \& TUG & Activity levels & Positive \\
\hline Toulotte et al., 2012 [35] & Active & Fully & RCT & $\begin{array}{l}36(65-85 \\
\text { yrs) }\end{array}$ & Tinetti, unipedal and Wii Fit & Balance & Positive \\
\hline Williams et al. 2010 [41] & Fallers & Partly & Qual. & $\begin{array}{l}21 \text { (over } 70 \\
\text { yrs) }\end{array}$ & BBS, TBAT, FES-I \& AFRIS & Balance, fear of falls \& Acceptance & Positive \\
\hline
\end{tabular}

